\title{
Comparison of the prognosis of four different treatment strategies for acute left malignant colonic obstruction: a systematic review and network meta-analysis
}

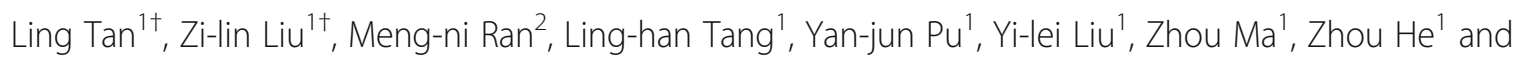
Jiang-wei Xiao ${ }^{1 *}$

\begin{abstract}
Background: There is controversy regarding the efficacy of different treatment strategies for acute left malignant colonic obstruction. This study investigated the 5-year overall survival (OS) and disease-free survival (DFS) of several treatment strategies for acute left malignant colonic obstruction.

Methods: We searched for articles published in PubMed, Embase (Ovid), MEDLINE (Ovid), Web of Science, and Cochrane Library between January 1, 2000, and July 1, 2020. We screened out the literature comparing different treatment strategies. Evaluate the primary and secondary outcomes of different treatment strategies. The network meta-analysis summarizes the hazard ratio, odds ratio, mean difference, and its $95 \%$ confidence interval.
\end{abstract}

Results: The network meta-analysis involved 48 articles, including 8 (randomized controlled trials) RCTs and 40 nonRCTs. Primary outcomes: the 5-year overall survival (OS) and disease-free survival (DFS) of the CS-BTS strategy and the DS-BTS strategy were significantly better than those of the ES strategy, and the 5-year OS of the DS-BTS strategy was significantly better than that of CS-BTS. The long-term survival of TCT-BTS was not significantly different from those of CS-BTS and ES. Secondary outcomes: compared with emergency resection (ER) strategies, colonic stent-bridge to surgery (CS-BTS) and transanal colorectal tube-bridge to surgery (TCT-BTS) strategies can significantly increase the primary anastomosis rate, CS-BTS and decompressing stoma-bridge to surgery (DS-BTS) strategies can significantly reduce mortality, and CS-BTS strategies can significantly reduce the permanent stoma rate. The hospital stay of DS-BTS is significantly longer than that of other strategies. There was no significant difference in the anastomotic leakage levels of several treatment strategies.

Conclusion: Comprehensive literature research, we find that CS-BTS and DS-BTS strategies can bring better 5-year OS and DFS than ER. DS-BTS strategies have a better 5-year OS than CS-BTS strategies. Without considering the hospital stays, DS-BTS strategy is the best choice.

Keywords: Colonic stenting, Transanal colorectal tube, Decompressing stoma, Bridge to surgery, Emergency resection, Acute left malignant colonic obstruction, Network meta-analysis

\footnotetext{
* Correspondence: xiaojiangwei2018@163.com

${ }^{+}$Ling Tan and Zi-lin Liu are the co-first authors in this study.

'Department of Gastrointestinal Surgery, Clinical Medical College and The

First Affiliated Hospital of Chengdu Medical College, Chengdu 610500,

Sichuan Province, China

Full list of author information is available at the end of the article
}

\section{$\triangle B M C$}

(c) The Author(s). 2021 Open Access This article is licensed under a Creative Commons Attribution 4.0 International License, which permits use, sharing, adaptation, distribution and reproduction in any medium or format, as long as you give appropriate credit to the original author(s) and the source, provide a link to the Creative Commons licence, and indicate if changes were made. The images or other third party material in this article are included in the article's Creative Commons licence, unless indicated otherwise in a credit line to the material. If material is not included in the article's Creative Commons licence and your intended use is not permitted by statutory regulation or exceeds the permitted use, you will need to obtain permission directly from the copyright holder. To view a copy of this licence, visit http://creativecommons.org/licenses/by/4.0/ The Creative Commons Public Domain Dedication waiver (http://creativecommons.org/publicdomain/zero/1.0/) applies to the data made available in this article, unless otherwise stated in a credit line to the data. 


\section{Background}

Colorectal cancer (CRC) is ranked third and second among global cancer morbidity and mortality, respectively. The incidence rate of CRC is third in men and fourth in women [1]. Approximately $30 \%$ of CRC patients have acute colonic obstruction, and the overall prognosis is poor [2]. Compared with elective surgery for CRC without left-sided malignant colonic obstruction, emergency resection (ER) with left-sided malignant colonic obstruction is associated with a higher risk of mortality and morbidity [3].

Twenty years ago, colonic stent (CS) implantation was first used to restore the lumen opening of patients with malignant obstruction of the left colon as a bridge to surgery (BTS) [4]. The current clinical treatments for patients with malignant obstruction of the left colon include CS-BTS, transanal colorectal tube (TCT)-BTS, decompressing stoma (DS)-BTS, and ER. Research on the treatment of left obstructive colorectal cancer is gradually increasing. A metaanalysis showed that CS-BTS improved short-term surgical outcomes compared with ER but had similar long-term tumor and survival outcomes [5]. Compared with TCT-BTS, CS-BTS in the treatment of acute left malignant intestinal obstruction had a higher decompression efficiency, safety, and technical success rate; had fewer complications; and could avoid the formation of stoma [6]; moreover, DS-BTS has more primary anastomoses than ER [7]. TCT-BTS can increase primary resection/anastomosis compared to ER, but the long-term outcomes are similar [8]. Although many RCTs and many standard paired meta-analyses have been published to date, upon comparing the available treatment strategies for left obstructive colorectal cancer, there is still controversy regarding the best treatment strategy.

An important disadvantage of these RCTs and standard pairwise meta-analyses on this topic is that they can only directly compare two treatments, not all available treatments at once. A network metaanalysis can simultaneously compare all treatment strategies available for left obstructive colorectal cancer. Another advantage of network meta-analysis is that it combines direct and indirect evidence from trials to facilitate indirect comparisons between multiple treatments that have not been directly studied before and comparative studies $[9,10]$. The purpose of this study was to conduct a systematic review of the literature to determine the relevant comparative treatment strategies available for left obstructive colorectal cancer, collect all published relevant data, and conduct a network meta-analysis to compare the longterm survival and short-term effects of the different treatment strategies.

\section{Methods}

\section{Search strategy and inclusion criteria}

A systematic search was performed based on the following databases: PubMed, Embase (Ovid), MEDLINE (Ovid), Web of Science, and Cochrane Library from January 1, 2000, to July 1, 2020. We used 'colorectal cancer', 'obstruction', 'colonic stent', 'transanal colorectal tube', decompressing stoma', 'bridge to surgery', 'emergency surgery', and corresponding free words to search the literature in the above databases, with the language restricted to English (The search strategy are in Supplementary Table 1). This network meta-analysis only considers report research in the form of articles, both RCT and non-RCT. Non-RCT studies must use intention-totreat analysis. To be included in the analysis, the article must compare two or more histologically confirmed treatment strategies for acute left malignant colonic obstruction, and the article must report at least one outcome of interest. If the study is based on the same database or patient population and reports the same results of interest, then unless the analysis is mutually exclusive, the reported results are different, or the results are measured, only the latest publications are included in the analysis. In the literature quality assessment, RCT literature is assessed based on Cochrane tools, and nonRCT literature is assessed based on Newcastle-Ottawa quality assessment Scale (NOS).

\section{Outcomes of interest}

1. Primary outcomes: 5-year overall survival (OS) and disease-free survival (DFS).

2. Secondary outcomes: primary anastomosis, mortality, anastomotic leak, permanent colostomy, and hospital stays.

\section{Data extraction}

First, all the identified titles and abstracts were examined by two independent reviewers (TL and LZL). Next, the same two reviewers independently examined the full texts of potentially relevant articles. In the event of disagreement, a third reviewer (RMN) was consulted, and the relevant articles were discussed until a consensus was reached. The following relevant information was extracted from all the included publications: treatment strategy, country, number of patients, age, tumor grade, surgery, and follow-up. For long-term survival outcomes, if available, the following data were extracted: hazard ratios (HRs), 95\% CI and $P$ values of OS and DFS. When the literature did not report HRs, only OS and DFS K-M curves, Engauge Digitizer (version 10.8) was used to determine the survival rates of the corresponding time points on the curve, followed by the HR calculation table [11]. All the data were independently extracted by two authors (TL and LZL) and compared for consistency. 


\section{Statistical analysis}

For each result of interest, we used STATA (version 15.3) to draw a network diagram of all treatments evaluated for that particular result. The network metaanalysis was performed using the Markov chain Monte Carlo method in WinBUGS 1.4. The results of the network meta-analysis involved the measurement of central tendency and post-standard deviation or confidence interval ( $\mathrm{CI})$. For binary results, the binomial model was used for analysis and the odds ratios (ORs) were calculated. For continuous results, the mean difference (MD) was calculated. For long-term results, the survival analysis model was used to calculate the HR. Modelling the treatment comparison between any two treatments (OR for binary results, MD for continuous results, and HR for long-term results) depends on the comparison between each individual treatment and an arbitrarily selected reference treatment. The reference treatment was chosen as the open method, and the likelihood of the treatment level (i.e., the treatment is rated as the best treatment, suboptimal treatment, suboptimal treatment, etc.) for each outcome of interest was calculated. The authors believe that a ranking probability of less than $90 \%$ is not high enough to be confidently reported as the correct ranking of surgical techniques of interest to this result [12].

We used residual deviation and deviation information criteria (DIC) to assess the heterogeneity between studies. We used three different models for each result: a fixed effects model, a random effects model, and a random effects inconsistent model. Model selection was based on model fitting. DIC provided a measure of model fit. If the DIC values between the fixed-effects model and the random-effects model were similar, a simpler model, the fixed-effects model, was used; if the fit of the random model represented by DIC was at least 3 lower than the fit of the fixed-effects model, the random-effects model was used [13, 14]. The data were evaluated for evidence of inconsistency between direct and indirect comparisons by examining the geometry $[13,14]$. In addition, the deviation and DIC statistics of consistent and inconsistent models were compared. If the inconsistent model had a better model fit than the consistent model, the network meta-analysis should be interpreted with caution [13-15].

\section{Results}

Our computer-aided search yielded 2705 publications from PubMed, MEDLINE (Ovid), Embase (Ovid), Web of Science, and Cochrane Library after removing the duplicate literature. By screening the titles and reading abstracts, we excluded another 2495 obviously irrelevant documents. Further full-text screening of 210 publications was carried out, and 161 articles were excluded
(Fig. 1). Ultimately, this network analysis contained 48 articles, including 7 RCT experiments (8 RCT literatures) [16-23] and 40 non-RCT experiments [8, 24-62]. The characteristics of the included studies (first author, journal, country, treatment strategy, basic characteristics of the study population, etc.) are summarized in Table 1. The risk of bias and literature quality assessment of each study included in the analysis are summarized in Supplementary Table 2. For RCT experiments, the risk of bias tool based on the Cochrane collaboration found that the quality of the included trials met the research standards. For non-RCT experiments, a NOS score of 7-9 indicates that the quality of the included trials meets the research standards.

\section{Overall analysis}

There were 35 [16-50] studies comparing CS-BTS and ER treatment strategies, 6 [51-56] studies comparing CS-BTS and DS-BTS treatment strategies, 5 [57-61] studies comparing CS-BTS and TCT-BTS treatment strategies, $4[54-56,62]$ studies comparing DS-BTS and ER treatment strategies, and $2[8,61]$ studies comparing TCT-BTS and ER treatment strategies. A total of 12,514 patients received 4 different treatment strategies: 3058 CS-BTS, 153 TCT-BTS, 775 DS-BTS, and 8528 ER. Figure 2 shows the network diagram of primary anastomosis. Similar network diagrams were constructed for all the results of interest. For all the results of interest, there was no evidence of inconsistency between the trials in the network because the DIC differences between the consensus model and the inconsistency model were not significant. The treatment strategies ranked from best to worst (1st to 4th) for the outcome of interest are summarized in Table 2. Among the four treatment strategies, the treatment strategy with the least primary anastomosis may be ER (95\% probability ER ranks 4th), while the best treatment strategy for 5-year OS was DSBTS (95\% probability DS-BTS ranks 1st). The treatment strategy with the longest hospital stay was DS-BTS, and the treatment strategy with the shortest hospital stay was TCT-BTS (100\% probability DS-BTS ranks 1st, and $100 \%$ probability TCT-BTS ranks 4 th).

\section{Primary outcomes}

Table 3 shows a pairwise comparison of the long-term results of several different treatment strategies (CS-BTS, TCT-BTS, DS-BTS and ER). For the 5-year overall survival rate, the evidence indicates that CS-BTS and DSBTS are significantly better than ER (ER Vs CS-BTS, DS-BTS, HR are 1.14 (1.04-1.26), 1.29 (1.13-1.48), respectively), and DS-BTS is significantly better than CSBTS (DS-BTS Vs CS-BTS HR are $0.88(0.80-0.98)$ ). For the 5-year DFS, the evidence indicates that CS-BTS and DS-BTS are significantly better than ER (ER Vs CS-BTS, 


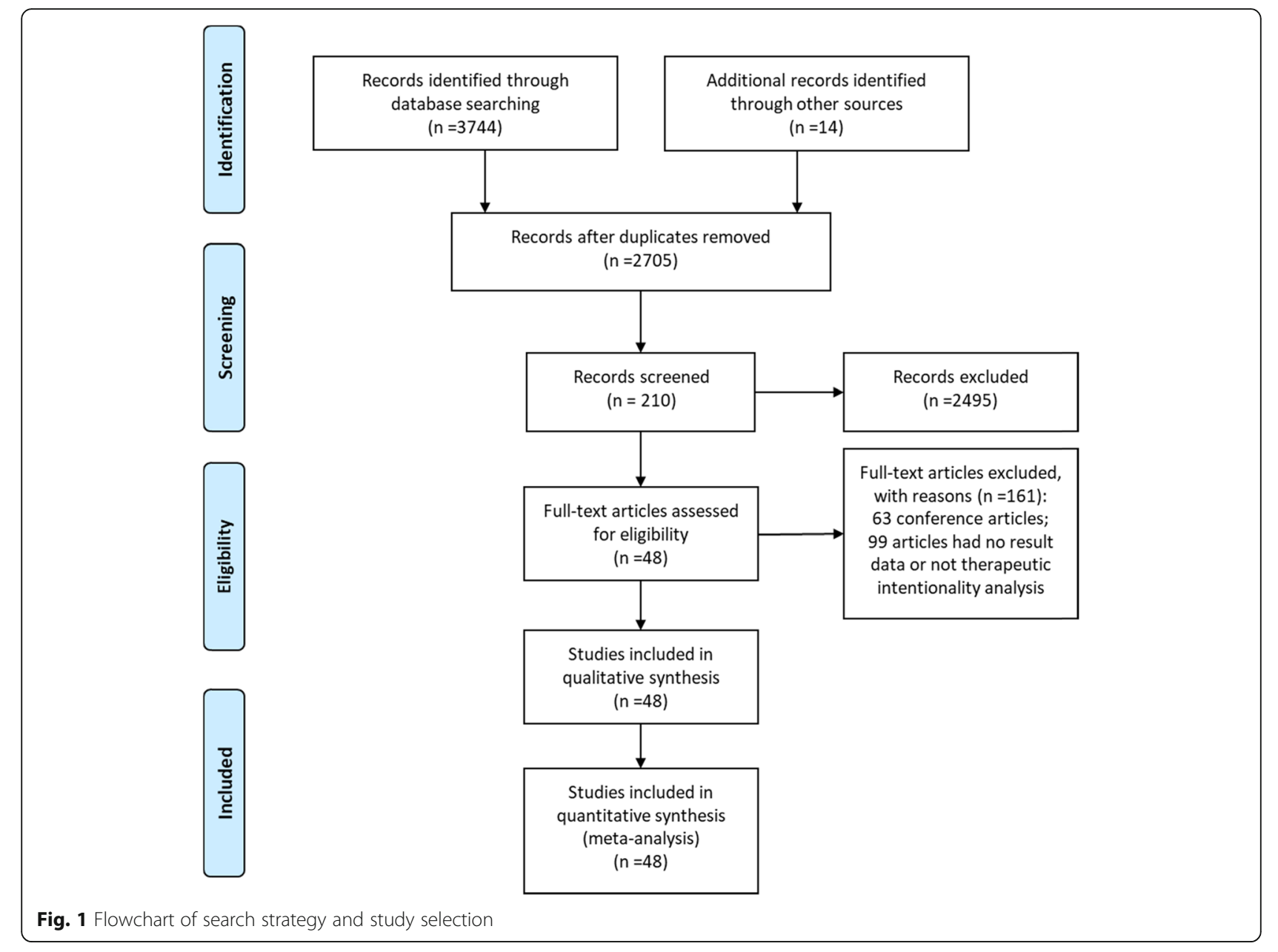

DS-BTS, HR are 1.12 (1.06-1.35), 1.23 (1.06-1.44), respectively). Compared with the other three treatment strategies, the TCT-BTS strategy had no significant differences in five-year OS and DFS.

\section{Secondary outcomes}

Table 4 shows a pairwise comparison of short-term postoperative outcomes between different treatment strategies. Paired comparison results showed that there was no significant difference in postoperative anastomotic leakage with different treatment strategies. Compared with ER, CS-BTS and TCT-BTS strategies can significantly increase the one-stage anastomosis rate; compared with ER, CS-BTS, and DS-BTS strategies can significantly reduce mortality; compared with ER, CSBTS can significantly reduce the rate of permanent stoma. In addition, the longest hospital stay was with DS-BTS, and the shortest was with TCT-BTS.

\section{Discussion}

This is the first network meta-analysis that can simultaneously compare several different treatment strategies for left-sided malignant colonic obstruction. The European Society of Gastrointestinal Endoscopy 2020 Guidelines recommend colon stents as a bridge to elective surgery in acute malignant obstruction of the left colon; at the same time, when the patient is not suitable for colonic stent placement, or when there is no professional for stent placement, decompression stoma is an effective choice as a bridge for selective surgery [63]. This network meta-analysis showed that patients with CS-BTS and DS-BTS strategies had a better prognosis than patients with ER strategies, while patients with DS-BTS strategies had better OS than patients with CS-BTS strategies. The previous standard paired meta-analysis and RCT comparison between CS-BTS and ER in the treatment of acute left colonic malignant obstruction proved that although CS-BTS increased the hospital stay, and it also increased the primary anastomosis rate. At the same time, postoperative complications, anastomotic leak, short-term mortality, wound infection, initial stoma, and permanent stoma were significantly reduced $[16,17,19,20,64-69]$. Similarly, our research proves that the CS-BTS strategy can increase primary 
Table 1 Characteristics of studies included in network meta-analysis of four different treatment strategies for the treatment of acute left malignant colonic obstruction

\begin{tabular}{|c|c|c|c|c|c|c|c|c|c|}
\hline $\begin{array}{l}\text { Author and year } \\
\text { of publication }\end{array}$ & Journal & $\begin{array}{l}\text { Treatment } \\
\text { strategy }\end{array}$ & Countries & $\begin{array}{l}\text { Sample } \\
\text { size }\end{array}$ & Age & Stage & $\begin{array}{l}\text { Operation } \\
\text { method }\end{array}$ & $\begin{array}{l}\text { Follow-up } \\
\text { (month) }\end{array}$ & $\begin{array}{l}\text { Study } \\
\text { design }\end{array}$ \\
\hline Okuda, 2019 [8] & Cancer Res Treat & TCT-BTS Vs ES & Japan & 46 & 72 VS 70 & $\begin{array}{l}\text { Stage II- } \\
\text { III }\end{array}$ & $\begin{array}{l}\text { Laparoscopic and } \\
\text { laparotomy }\end{array}$ & 60 & no-RCT \\
\hline Jiang 2008 [62] & Dis Colon Rectum & DS-BTS Vs ES & China & 143 & 68.2 VS 67.4 & Stage I-III & - & 120 & no-RCT \\
\hline Amelung, 2016 [51] & Surg Endosc & $\begin{array}{l}\text { CS-BTS Vs DS- } \\
\text { BTS }\end{array}$ & Dutch & 88 & 71.8 VS 66.6 & Stage I-IV & $\begin{array}{l}\text { Laparoscopic and } \\
\text { laparotomy }\end{array}$ & 46 & no-RCT \\
\hline Mege, 2019 [52] & Ann Surg Oncol & $\begin{array}{l}\text { CS-BTS VS DS- } \\
\text { BTS }\end{array}$ & France & 518 & 72 VS 71 & Stage I-IV & - & 140 & no-RCT \\
\hline Veld, 2020 [53] & JAMA Surgery & $\begin{array}{l}\text { CS-BTS Vs DS- } \\
\text { BTS }\end{array}$ & Dutch & 242 & 70.1 VS 69.8 & uncertain & $\begin{array}{l}\text { Laparoscopic and } \\
\text { laparotomy }\end{array}$ & 32 & no-RCT \\
\hline Kagami, 2018 [58] & World J Surg Oncol & $\begin{array}{l}\text { CS-BTS Vs } \\
\text { TCT-BTS }\end{array}$ & Japan & 59 & 70 VS 68 & $\begin{array}{l}\text { Stage II- } \\
\text { IV }\end{array}$ & $\begin{array}{l}\text { Laparoscopic and } \\
\text { laparotomy }\end{array}$ & - & no-RCT \\
\hline Sato 2019 [59] & $\begin{array}{l}\text { Ann Gastroenterol } \\
\text { Surg }\end{array}$ & $\begin{array}{l}\text { CS-BTS Vs } \\
\text { TCT-BTS }\end{array}$ & Japan & 76 & 70.8 VS 76.0 & $\begin{array}{l}\text { Stage II- } \\
\text { III }\end{array}$ & $\begin{array}{l}\text { Laparoscopic and } \\
\text { laparotomy }\end{array}$ & 30 & no-RCT \\
\hline Yang, 2019, [60] & Oncology Letters & $\begin{array}{l}\text { CS-BTS Vs } \\
\text { TCT-BTS }\end{array}$ & China & 89 & $\begin{array}{l}50.64 \text { VS } \\
52.04\end{array}$ & Stage I-IV & $\begin{array}{l}\text { Laparoscopic and } \\
\text { laparotomy }\end{array}$ & 12 & no-RCT \\
\hline Hosono 2019 [57] & $\begin{array}{l}\text { Asian J Endosc } \\
\text { Surg }\end{array}$ & $\begin{array}{l}\text { CS-BTS VS } \\
\text { TCT-BTS }\end{array}$ & Japan & 42 & 74 VS 74 & $\begin{array}{l}\text { Stage II- } \\
\text { IV }\end{array}$ & $\begin{array}{l}\text { Laparoscopic and } \\
\text { laparotomy }\end{array}$ & 21 & no-RCT \\
\hline Kawachi, 2018 [61] & ASIAN J SURG & $\begin{array}{l}\text { CS-BTS Vs } \\
\text { TCT-BTS Vs ES }\end{array}$ & Japan & 56 & $\begin{array}{l}69.4 \text { VS } 74.1 \\
\text { VS } 68.9\end{array}$ & $\begin{array}{l}\text { Stage II- } \\
\text { IV }\end{array}$ & - & - & no-RCT \\
\hline Amelung, 2016 [54] & Ann Surg Oncol & $\begin{array}{l}\text { CS-BTS Vs DS- } \\
\text { BTS Vs ES }\end{array}$ & Dutch & 1860 & $\begin{array}{l}69.9 \text { VS } 64.9 \\
\text { VS } 71.4\end{array}$ & uncertain & $\begin{array}{l}\text { Laparoscopic and } \\
\text { laparotomy }\end{array}$ & - & no-RCT \\
\hline Oistamo, 2016 [55] & World J Surg Ocol & $\begin{array}{l}\text { CS-BTS Vs DS- } \\
\text { BTS Vs ES }\end{array}$ & Sweden & 100 & $\begin{array}{l}71 \text { VS } 67 \text { VS } \\
74\end{array}$ & $\begin{array}{l}\text { Stage II- } \\
\text { IV }\end{array}$ & - & - & no-RCT \\
\hline Tanis, 2015 [56] & Digestive Surgery & $\begin{array}{l}\text { CS-BTS Vs DS- } \\
\text { BTS Vs ES }\end{array}$ & Dutch & 1816 & $\begin{array}{l}71 \text { VS } 68 \text { VS } \\
70\end{array}$ & Stage I-IV & $\begin{array}{l}\text { Laparoscopic and } \\
\text { laparotomy }\end{array}$ & - & no-RCT \\
\hline Amelung, 2017 [24] & Surg Endosc & CS-BTS Vs ES & Dutch & 110 & 70VS70.4 & $\begin{array}{l}\text { Stage II- } \\
\text { IV }\end{array}$ & $\begin{array}{l}\text { Laparoscopic and } \\
\text { laparotomy }\end{array}$ & 44 & no-RCT \\
\hline Arezzo, 2017 [16] & Surg Endosc & CS-BTS Vs ES & Italy & 115 & 72 VS 71 & uncertain & $\begin{array}{l}\text { Laparoscopic and } \\
\text { laparotomy }\end{array}$ & 36 & RCT \\
\hline Chen, 2019 [25] & $\begin{array}{l}\text { World } \\
\text { JGastroenterol }\end{array}$ & CS-BTS Vs ES & China & 128 & $\begin{array}{l}63.21 \text { VS } \\
61.58\end{array}$ & Stage I-IV & - & - & no-RCT \\
\hline Choi, 2014 [26] & Surg Endosc & CS-BTS Vs ES & Korea & 240 & 65.2 VS 64.8 & $\begin{array}{l}\text { Stage II- } \\
\text { IV }\end{array}$ & - & 41.4 VS 45 & no-RCT \\
\hline Consolo, 2017 [27] & Turk J Gastroenterol & CS-BTS Vs ES & Italy & 125 & 74.2 VS 70 & Stage I-IV & - & - & no-RCT \\
\hline Erichsen, 2015 [29] & Endoscopy & CS-BTS Vs ES & Denmark & 3914 & - & - & - & 24 & no-RCT \\
\hline $\begin{array}{l}\text { Flor-Lorente, } 2017 \\
\text { [30] }\end{array}$ & Cirugia Espanola & CS-BTS Vs ES & Spain & 82 & 72 VS 70 & Stage I-IV & $\begin{array}{l}\text { Laparoscopic and } \\
\text { laparotomy }\end{array}$ & 58 & no-RCT \\
\hline Ghazal, 2013 [18] & J Gastrointest Surg & CS-BTS Vs ES & Egypt & 60 & 52 VS51 & Stage I-III & Laparotomy & 18 & RCT \\
\hline Gorissen, J.2013 [31] & Br J Surg & CS-BTS Vs ES & England & 105 & 70.6VS72.0 & Stage I-IV & $\begin{array}{l}\text { Laparoscopic and } \\
\text { laparotomy }\end{array}$ & 32 VS33 & no-RCT \\
\hline Han, 2020 [33] & PAK J MED SCI & CS-BTS Vs ES & China & 302 & $\begin{array}{l}60.25 \mathrm{VS} \\
61.03\end{array}$ & $\begin{array}{l}\text { Stage II- } \\
\text { IV }\end{array}$ & - & $\begin{array}{l}45.82 \text { VS44, } \\
92\end{array}$ & no-RCT \\
\hline Ho, 2017 [34] & Surgical Endoscopy & CS-BTS Vs ES & China & 102 & 70.2 VS 70.9 & Stage I-IV & $\begin{array}{l}\text { Laparoscopic and } \\
\text { laparotomy }\end{array}$ & 21 VS 25.5 & no-RCT \\
\hline Ho, 2012 [19] & Int J Colorectal Dis & CS-BTS Vs ES & Singapore & 39 & 68 VS 65 & $\begin{array}{l}\text { Stage II- } \\
\text { IV }\end{array}$ & $\begin{array}{l}\text { Laparoscopic and } \\
\text { laparotomy }\end{array}$ & - & RCT \\
\hline Kavanagh, 2013 [35] & Dis Colon Rectum & CS-BTS Vs ES & Ireland & 49 & 69.9 VS 69.7 & Stage I-III & $\begin{array}{l}\text { Laparoscopic and } \\
\text { laparotomy }\end{array}$ & 27.4 VS 26 & no-RCT \\
\hline Kim, 2016 [36] & ANZ J Surg & CS-BTS Vs ES & Korea & 168 & 64.6 VS 64.5 & uncertain & $\begin{array}{l}\text { Laparoscopic and } \\
\text { laparotomy }\end{array}$ & 45 VS 49.5 & no-RCT \\
\hline Kim, 2015 [37] & Surg Endosc & CS-BTS Vs ES & Korea & 56 & 64.6 VS 70.7 & Stage II- & Laparoscopic and & 30 VS 26 & no-RCT \\
\hline
\end{tabular}


Table 1 Characteristics of studies included in network meta-analysis of four different treatment strategies for the treatment of acute left malignant colonic obstruction (Continued)

\begin{tabular}{|c|c|c|c|c|c|c|c|c|c|}
\hline $\begin{array}{l}\text { Author and year } \\
\text { of publication }\end{array}$ & Journal & $\begin{array}{l}\text { Treatment } \\
\text { strategy }\end{array}$ & Countries & $\begin{array}{l}\text { Sample } \\
\text { size }\end{array}$ & Age & Stage & $\begin{array}{l}\text { Operation } \\
\text { method }\end{array}$ & $\begin{array}{l}\text { Follow-up } \\
\text { (month) }\end{array}$ & $\begin{array}{l}\text { Study } \\
\text { design }\end{array}$ \\
\hline & & & & & & IV & laparotomy & & \\
\hline Kwak, 2016 [38] & Dis Colon Rectum & CS-BTS Vs ES & Korea & 84 & 62 VS 60 & Stage I-IV & $\begin{array}{l}\text { Laparoscopic and } \\
\text { laparotomy }\end{array}$ & 44 & no-RCT \\
\hline Lee, 2013 [39] & Int J Surg & CS-BTS Vs ES & Korea & 77 & 63.6 VS 56.6 & Stage I-IV & $\begin{array}{l}\text { Laparoscopic and } \\
\text { laparotomy }\end{array}$ & 38.7 & no-RCT \\
\hline Lim, 2017 [40] & Ann Surg Oncol & CS-BTS Vs ES & Singapore & 102 & 65 VS 66 & Stage I-III & $\begin{array}{l}\text { Laparoscopic and } \\
\text { laparotomy }\end{array}$ & 48 & no-RCT \\
\hline Lovero, 2020 [41] & Eur J Clin Invest & CS-BTS Vs ES & Italy & 45 & 64.7 VS 71.2 & Stage I-IV & $\begin{array}{l}\text { Laparoscopic and } \\
\text { laparotomy }\end{array}$ & 15 & no-RCT \\
\hline Morita, 2019 [42] & Surg Today & CS-BTS Vs ES & Japan & 201 & 74 VS 70 & Stage I-IV & $\begin{array}{l}\text { Laparoscopic and } \\
\text { laparotomy }\end{array}$ & - & no-RCT \\
\hline Park, 2018 [44] & Int J Colorectal Dis & CS-BTS Vs ES & Korea & 111 & 64 VS 69 & Stage I-IV & $\begin{array}{l}\text { Laparoscopic and } \\
\text { laparotomy }\end{array}$ & 58.2 VS 50.4 & no-RCT \\
\hline Park, 2016 [45] & Ann Surg Oncol & CS-BTS Vs ES & Korea & 102 & 68.6 VS 63.1 & Stage I-III & $\begin{array}{l}\text { Laparoscopic and } \\
\text { laparotomy }\end{array}$ & 35.7 VS 46.6 & no-RCT \\
\hline Pirlet, 2011 [20] & Surg Eedosc & CS-BTS Vs ES & France & 60 & 70.4 VS 74.7 & uncertain & Laparotomy & - & $\mathrm{RCT}$ \\
\hline $\begin{array}{l}\text { Rodrigues-Pinto, } \\
2019 \text { [46] }\end{array}$ & Dig Liver Dis & CS-BTS Vs ES & Italy & 94 & 67 VS 75 & Stage I-IV & $\begin{array}{l}\text { Laparoscopic and } \\
\text { laparotomy }\end{array}$ & 24 VS 30 & no-RCT \\
\hline Sabbagh, 2013 [47] & Ann Surg & CS-BTS Vs ES & France & 87 & $\begin{array}{l}69.73 \text { VS } \\
74.89\end{array}$ & Stage I-IV & $\begin{array}{l}\text { Laparoscopic and } \\
\text { laparotomy }\end{array}$ & 28 VS 32 & no-RCT \\
\hline Sloothaak, 2014 [21] & $\mathrm{Br} J$ Surg & CS-BTS Vs ES & Dutch & 58 & 70 VS 67 & Stage I-IV & - & 45 VS 41 & $\mathrm{RCT}$ \\
\hline $\begin{array}{l}\text { van den Berg, } 2014 \\
\text { [48] }\end{array}$ & Br J Surg & CS-BTS Vs ES & Dutch & 110 & 71 VS 72 & Stage I-IV & $\begin{array}{l}\text { Laparoscopic and } \\
\text { laparotomy }\end{array}$ & - & no-RCT \\
\hline Yan, 2017 [49] & $\begin{array}{l}\text { J Laparoendosc } \\
\text { Adv Surg Tech A }\end{array}$ & CS-BTS Vs ES & China & 60 & $\begin{array}{l}60.44 \text { VS } \\
59.36\end{array}$ & $\begin{array}{l}\text { Stage II- } \\
\text { IV }\end{array}$ & - & - & no-RCT \\
\hline Yang, 2019 [50] & Ann Surg Oncol & CS-BTS Vs ES & Korea & 253 & 65.2 VS 63.9 & Stage I-III & $\begin{array}{l}\text { Laparoscopic and } \\
\text { laparotomy }\end{array}$ & 60.4 VS 53.4 & no-RCT \\
\hline van Hooft 2011 [23] & The lancet & CS-BTS Vs ES & Dutch & 98 & 70.4 VS 71.4 & uncertain & - & 39 VS 44 & $\mathrm{RCT}$ \\
\hline $\begin{array}{l}\text { Cheung, 2009/2012 } \\
{[17,22]}\end{array}$ & $\begin{array}{l}\text { Arch Surg/Asian J } \\
\text { Endosc Surg }\end{array}$ & CS-BTS Vs ES & China & 48 & 64.5 VS 68.5 & Stage I-IV & $\begin{array}{l}\text { Laparoscopic and } \\
\text { laparotomy }\end{array}$ & 65 VS 32 & $\mathrm{RCT}$ \\
\hline Guo 2011 [32] & Dig Dis Sci & CS-BTS Vs ES & China & 92 & 77 VS 76 & uncertain & - & - & no-RCT \\
\hline $\mathrm{Ng} 2006$ [43] & J Gastrointest Surg & CS-BTS Vs ES & China & 60 & 74 VS 73.5 & $\begin{array}{l}\text { Stage II- } \\
\text { IV }\end{array}$ & $\begin{array}{l}\text { Laparoscopic and } \\
\text { laparotomy }\end{array}$ & - & no-RCT \\
\hline Dastur 2008 [28] & Tech Coloproctol & CS-BTS Vs ES & England & 42 & 75 VS 68 & uncertain & & 21 VS 30 & no-RCT \\
\hline
\end{tabular}

anastomosis and reduce permanent stoma and shortterm mortality compared with the ER strategy. Previous paired meta-analyses and RCT comparisons of CS-BTS and ER in the treatment of acute left colonic malignant obstruction proved that the long-term results are similar $[5,16,21,22,70-74]$, but our study proved that the long-term survival of CS-BTS is better than that of ER. The reasons for our analysis are as follows: ER often belongs to the state of incomplete surgical preparation, the general nutritional and immune status of patients is worse, and it is more likely to lead to tumor recurrence; longer recovery time after ER may lead to delayed chemotherapy; ER pays more attention to speed while neglecting lymph node dissection. Under these comprehensive factors, the long-term survival rate of ER is even worse. At same time, it may also be because we included more studies and the analysis method of the included studies adopted an intention-to-treat analysis.

Early research shows that, compared with the ER strategy, the DS-BTS strategy is a safe and effective treatment for acute left obstructive colon cancer [7]. Although the DS-BTS strategy had the same early mortality, complications, and anastomotic leakage as the ER strategy, the DS-BTS strategy increased the length of hospital stay and resulted in a significant increase in primary anastomosis and a significant decrease in permanent stoma [7, $54,55,62]$. This network meta-analysis found that the anastomotic leakage and length of hospital stay were similar in the previous study, but our study showed that the early mortality rate of the DS-BTS strategy was 


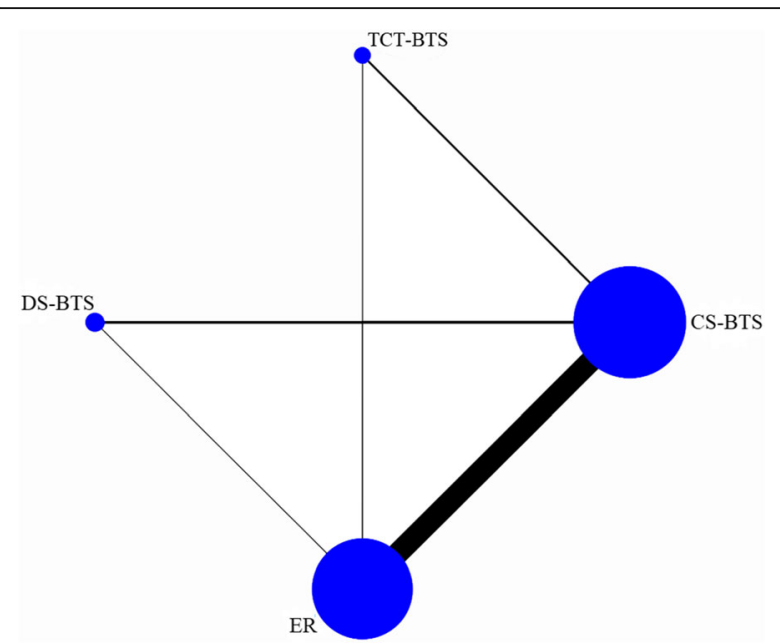

Fig. 2 The network diagram of primary anastomosis

significantly lower than that of the ER strategy. The difference in this strategy may be that DS-BTS is divided into two operations, the first operation is relatively small, and the surgical trauma is relatively small, so the early mortality rate is relatively low. The DS-BTS strategy requires two operations, which increases the patient's hospital stay and costs [75]. Our study proved that the 5year OS and DFS of the DS-BTS strategy are significantly better than those of the ER strategy. The DS-BTS strategy increases the patient's hospital stay and costs but returns good long-term survival. Previous studies have proved that compared with the ER strategy, the DS-BTS strategy can significantly increase the production of lymph nodes [55], which is an important prognostic factor for colorectal malignancies. Perhaps because of this increased lymph node production, the obstructive colorectal cancer 5-year OS is significantly increased. This may be one of the important reasons why DS-BTS strategy leads to better 5-year OS and DFS than ER strategy.
Previous meta-analyses and RCTs showed that the CSBTS strategy has fewer complications, a lower stoma rate, a higher primary anastomosis rate, and higher technical and clinical success rates than the TCT-BTS strategy in the treatment of acute left malignant intestinal obstruction $[6,76,77]$. Perhaps because the guide wire of the stent is small, it is easy to pass through the narrow part of the region. At the same time, when the stent is placed, the guide wire is more likely to make the stent reach the front end of the tumor [6], resulting in higher technical and clinical success rates of the CS-BTS strategy than the TCT-BTS strategy. Compared with the CS decompression strategy, the TCT strategy has an equivalent decompression effect [78]. However, patients with the TCT-BTS strategy require long-term retention of the anal decompression tube in the anus, which is associated with a great psychological burden and a bad mental state, which may be the reason for the worse prognosis compared to CS-BTS. Compared with the ER strategy, the TCT-BTS strategy has similar permanent stoma, short-term mortality, and long-term survival rates, but it increases the primary anastomosis rate $[8$, 61]. This network meta-analysis showed that there were no significant differences between the CS-BTS strategy and the TCT-BTS strategy in terms of primary anastomosis, mortality, anastomotic leakage, permanent stoma, and long-term survival. At the same time, the TCT-BTS and ER strategies have similar permanent stoma rates, short-term mortality, and long-term survival, and the increased primary anastomosis rates are similar to previous studies.

Compared with elective surgery for CRC without left malignant colon obstruction, emergency surgery with left malignant colon obstruction usually requires multiple operations, prolongs the hospital stay, and is associated with higher mortality and morbidity [3]. Current research shows that for curable acute left-sided malignant colonic obstruction patients, CS and DS are both effective decompression methods [51], but there is still

Table 2 Probability of Ranking From Best to Worst (1st-4th) for the Outcomes of Interest

\begin{tabular}{lllll}
\hline Outcomes & Ranks & & \\
\cline { 2 - 4 } & $\mathbf{1}$ st & 2nd & 3rd & 4th \\
\hline Primary anastomosis & TCT-BTS $P=0.46$ & CS-BTS $P=0.48$ & DS-BTS $P=0.63$ & ER $\boldsymbol{P}=\mathbf{0 . 9 5}$ \\
Mortality & ER $P=0.68$ & TCT-BTS $P=0.38$ & CS-BTS $P=0.65$ & DS-BTS $P=0.76$ \\
Anastomotic leak & TCT-BTS $P=0.59$ & ER $P=0.53$ & CS-BTS $P=0.54$ & DS-BTS $P=0.62$ \\
Permanent colostomy & ER $P=0.77$ & TCT-BTS $P=0.52$ & CS-BTS $P=0.5$ & DS-BTS $P=0.48$ \\
Hospital stays & DS-BTS $\boldsymbol{P}=\mathbf{1}$ & ER $\boldsymbol{P}=\mathbf{0 . 9 5}$ & CS-BTS $\boldsymbol{P}=\mathbf{0 . 9 5}$ & TCT-BTS $\boldsymbol{P}=\mathbf{1}$ \\
Five-year DFS & DS-BTS $P=0.68$ & CS-BTS $P=0.673$ & ER $P=0.56$ & TCT-BTS $P=0.57$ \\
Five-year OS & DS-BTS $\boldsymbol{P}=\mathbf{0 . 9 5}$ & CS-BTS $P=0.87$ & ER $P=0.72$ & TCT-BTS $P=0.72$ \\
\hline
\end{tabular}

Ranking with more than $90 \%$ probability is highlighted in bold. A probability of ranking below $90 \%$ was not considered by the authors to be high enough to be confidently reported as the correct ranking position of a treatment strategy for that outcome of interest 
Table 3 Pairwise comparisons for 5-year survival outcomes

\begin{tabular}{|c|c|c|c|c|}
\hline \multirow[t]{2}{*}{ DFS } & \multirow[t]{2}{*}{ CS-BTS } & \multirow{2}{*}{$\begin{array}{l}\text { TCT-BTS } \\
1.23(0.88-1.72)\end{array}$} & \multirow{2}{*}{$\begin{array}{l}\text { DS-BTS } \\
0.97(0.88-1.07)\end{array}$} & \multirow{2}{*}{$\begin{array}{l}\text { ER } \\
1.12(1.06-1.35)\end{array}$} \\
\hline & & & & \\
\hline & -BTS & - & $0.79(0.56-1.12)$ & $0.97(0.70-1.36)$ \\
\hline & DS-BTS & - & - & $1.23(1.06-1.44)$ \\
\hline \multirow[t]{3}{*}{ OS } & CS-BTS & $1.29(0.85-1.97)$ & $0.88(0.80-0.98)$ & $1.14(1.04-1.26)$ \\
\hline & TCT-BTS & - & $0.68(0.45-1.05)$ & $0.89(0.59-1.34)$ \\
\hline & DS-BTS & - & - & $1.29(1.13-1.48)$ \\
\hline
\end{tabular}

Hazard ratio horizontal treatment over vertical treatment (95\% credible intervals $\mathrm{Cl}$ )

controversy regarding the prognosis of tumors [52-54]. At the same time, the DS-BTS strategy requires more temporary colostomies and incisional hernias [51]. The DS-BTS strategy requires more surgical procedures to reinstate the stoma and repair the incision hernia. This network meta-analysis found that all short-term results of CS-BTS and DS-BTS were similar, except that the hospital stay in DS-BTS was longer. However, the longterm result is that the 5-year OS of the DS-BTS strategy is significantly better than that for the CS-BTS strategy. DS-BTS offers a better long-term survival than CS-BTS, which can be accompanied by some serious complications, including stent re-blocking, displacement, and intestinal perforation [79], and ER might be necessary, which could cause a poor prognosis. The abovementioned complications after DS-BTS decompression are relatively rare. It is worthwhile to implement a DS-BTS strategy for a better 5-year survival, notwithstanding a longer hospital stay and reoperation rate due to DS-BTS.

This network meta-analysis yielded short-term results similar to those of previous studies. In addition, we also obtained the long-term survival results of several treatment strategies. CS-BTS and DS-BTS significantly increased the 5-year OS compared with ER. Early largescale studies and RCTs have shown that for acute left colonic obstructive malignant tumors, surgery after the remission of intestinal obstruction can significantly improve the short-term outcome (mortality [19, 54], primary anastomosis [8], stoma $[16,17,20,61])$. For example, after the intestinal obstruction is relieved, the decrease of the stomata rate is related to the relief of oedema in the intestinal tract [80]. It is possible that relief of edema in the intestinal tract can increase primary anastomoses, decrease anastomotic leakage, and decrease mortality. Finally, it seems that in the treatment of acute left obstructive colonic malignancies, preoperative removal of the obstruction can improve the patient's 5 -year OS and DFS (whether it is CS-BTS or DS-BTS), possibly because the removal of intestinal obstruction can improve the patient's nutritional status, enhance immunity, provide the opportunity to prepare the bowel, reduce the state of inflammatory stress, and increase the tumor R0 resection rate and more thorough lymph node dissection.

This research involves several limitations that must be considered. Since there are only 8 RCTs in the included

Table 4 Pairwise comparisons for short-term postoperative outcomes

\begin{tabular}{|c|c|c|c|c|}
\hline & & TCT-BTS & DS-BTS & ER \\
\hline \multirow[t]{3}{*}{ Primary anastomosis* } & CS-BTS & $0.98(0.26-3.71)$ & $0.61(0.22-1.68)$ & $0.23(0.13-0.38)$ \\
\hline & TCT-BTS & - & $0.63(0.12-3.05)$ & $0.23(0.06-0.84)$ \\
\hline & DS-BTS & - & - & $0.37(0.13-1.06)$ \\
\hline \multirow[t]{3}{*}{ Mortality* } & CS-BTS & $1.48(0.29-6.29)$ & $0.71(0.35-1.23)$ & $2.13(1.59-3.22)$ \\
\hline & TCT-BTS & - & $0.48(0.10-2.61)$ & $1.45(0.35-8.01)$ \\
\hline & DS-BTS & - & - & $3.03(1.75-6.67)$ \\
\hline \multirow[t]{3}{*}{ Anastomotic leak* } & CS-BTS & $1.69(0.35-7.88)$ & $0.75(0.22-2.21)$ & $1.33(0.84-2.21)$ \\
\hline & TCT-BTS & - & $0.45(0.07-3.11)$ & $0.79(0.17-3.89)$ \\
\hline & DS-BTS & - & - & $1.77(0.61-6.11)$ \\
\hline \multirow[t]{3}{*}{ Permanent colostomy* } & CS-BTS & $1.89(0.50-7.14)$ & $0.98(0.27-3.51)$ & $3.28(1.75-6.41)$ \\
\hline & TCT-BTS & - & $0.52(0.08-3.34)$ & $1.75(0.45-6.77)$ \\
\hline & DS-BTS & - & - & $3.35(0.88-14.07)$ \\
\hline \multirow[t]{3}{*}{ Hospital stayst } & CS-BTS & $-15.35(-25.43-5.13)$ & $13.76(9.13-18.03)$ & $2.10(-0.44-5.27)$ \\
\hline & TCT-BTS & - & $29.00(18.02-39.73)$ & $17.46(6.24-27.77)$ \\
\hline & DS-BTS & - & - & $-11.58(-15.60-6.77)$ \\
\hline
\end{tabular}

Statistically significant outcomes in bold: OR was significant if the $95 \% \mathrm{Cl}$ did not include the value $1, \mathrm{MD}$ was significant if the $95 \% \mathrm{Cl}$ did not include the value 0 "Odds ratio of horizontal treatment over vertical treatment

${ }^{\dagger}$ Mean difference of horizontal treatment minus vertical treatment, (95\% credible intervals $\mathrm{Cl}$ ) 
48 articles, and the RCT studies compared CS-BTS and ES, other treatment strategy studies are non-RCTs, which may cause some deviations in the results. The inclusion criteria limit the need for intentional analysis; this deviation should be minimized as much as possible.

\section{Conclusion}

In comprehensive literature research, we find that CSBTS and DS-BTS strategies can bring better 5-year OS and DFS than ER. DS-BTS strategies have a better 5year OS than CS-BTS strategies. Without considering the hospital stays, DS-BTS strategy is the best choice.

\section{Abbreviations}

CRC: Colorectal cancer; RCT: Randomized controlled trial; ER: Emergency resection; CS: Colonic stent; BTS: Bridge to surgery; TCT: Transanal colorectal tube; DS: Decompressing stoma; CS-BTS: Colonic stent-bridge to surgery; TCT-BTS: Transanal colorectal tube-bridge to surgery; DS-BTS: Decompressing stoma-bridge to surgery; NOS: Newcastle-Ottawa quality assessment Scale; DFS: Disease-free survival; OS: Overall survival; HR: Hazard ratio;

Cl: Confidence interval; MD: Mean difference; OR: Odds ratio; DIC: Deviation information criteria

\section{Supplementary Information}

The online version contains supplementary material available at https://doi. org/10.1186/s13017-021-00355-2.

Additional file 1: Table 1. Literature search strategy. Table 2 Assessment of Methodological Quality of Studies Included

\section{Acknowledgements}

We are very grateful to Ni Ran for providing guidance on search strategies for this study.

\section{Authors' contributions \\ Ling Tan and Zi-lin Liu: acquisition of data, analysis and interpretation of data, drafting the article, and final approval; Meng-ni Ran, Ling-han Tang, and Yan-jun Pu: interpretation of data, revising the article, and final approval; Yi-lei Liu, Zhou Ma, and Zhou He: revising the article and final approval; Jiang-wei Xiao: conception and design of the study, critical revision, and final approval. The authors read and approved the final manuscript. \\ Funding \\ National Natural Science Foundation of China, NO.81070378 and NO. 81270561; Special Research Fund for the First Affiliated Hospital of Chengdu Medical College, NO.CYFY2019YB08; and High-level Talents Introduction Fund for the First Affiliated Hospital of Chengdu Medical College, NO.CYFY2018GQ17.}

\section{Availability of data and materials}

The datasets used and analyzed during the current study are available from the corresponding author on reasonable request.

\section{Declarations}

Ethics approval and consent to participate

Not applicable.

\section{Consent for publication}

Not applicable.

\section{Competing interests}

The authors declare that they have no competing interests.

\section{Author details}

'Department of Gastrointestinal Surgery, Clinical Medical College and The First Affiliated Hospital of Chengdu Medical College, Chengdu 610500, Sichuan Province, China. ${ }^{2}$ State Key Laboratory of Biotherapy West China Hospital, West China Medical School, Sichuan University, Chengdu 610500, Sichuan Province, China.

Received: 13 November 2020 Accepted: 23 February 2021

Published online: 18 March 2021

\section{References}

1. Bray F, Ferlay J, Soerjomataram I. Global cancer statistics 2018: GLOBOCAN estimates of incidence and mortality worldwide for 36 cancers in 185 countries. CA Cancer J Clin. 2018;68(6):394-424.

2. Okuda Y, Shimura T, Yamada T, Hirata Y, Yamaguchi R, Sakamoto E, HJljoco K. Colorectal obstruction is a potential prognostic factor for stage ॥ colorectal cancer. Int J Clin Oncol. 2018;23(6):1101-11.

3. Biondo S, Parés D, Frago R, Martí-Ragué J, Kreisler E, De Oca J, EJDotc J. Rectum: Large bowel obstruction: predictive factors for postoperative mortality. Dis Colon Rectum. 2004:47(11):1889-97.

4. Tejero E, Mainar A, Fernández L, Tobío R, MJDotc DG. Rectum: New procedure for the treatment of colorectal neoplastic obstructions. Dis Colon Rectum. 1994;37(11):1158-9.

5. Spannenburg L, Sanchez Gonzalez M, Brooks A, Wei S, Li X, Liang X, Gao W, Wang $\mathrm{H}$. Surgical outcomes of colonic stents as a bridge to surgery versus emergency surgery for malignant colorectal obstruction: a systematic review and meta-analysis of high quality prospective and randomised controlled trials. Eur J Surg Oncol. 2020;46(8):1404-14.

6. Xu J, Zhang S, Jiang T, Zhao YJ. Transanal drainage tubes vs metallic stents for acute malignant left-sided bowel obstruction: a systematic review and meta-analysis. Medicine. 2020;99(2):e18623.

7. Amelung FJ, Mulder CLJ, Verheijen PM, Draaisma WA, Siersema PD, Consten ECJ. Acute resection versus bridge to surgery with diverting colostomy for patients with acute malignant left sided colonic obstruction: systematic review and meta-analysis. Surg Oncol. 2015;24(4):313-21.

8. Okuda Y, Yamada T, Hirata Y, Shimura T, Yamaguchi R, Sakamoto E, Sobue S, Nakazawa T, Kataoka H, Joh T. Long-term outcomes of one stage surgery using transanal colorectal tube for acute colorectal obstruction of stage II/III distal colon cancer. Cancer Res Treat. 2019;51(2):474-82.

9. Jansen J, HJBm N. Is network meta-analysis as valid as standard pairwise metaanalysis? It all depends on the distribution of effect modifiers. BMC Med. 2013; 11:159.

10. Mills E, loannidis J, Thorlund K, Schünemann H, Puhan M, GJJ G. How to use an article reporting a multiple treatment comparison meta-analysis. JAMA. 2012;308(12):1246-53.

11. Tierney JF, Stewart LA, Ghersi D. Practical methods for incorporating summary time-to-event data into meta-analysis. Trials. 2007;8:16.

12. Dias S, Welton NJ, Sutton AJ, Ades AE. Evidence synthesis for decision making 1: introduction. Med Dec Mak. 2013;33(5):597-606.

13. Dias S, Sutton AJ, Welton NJ, Ades AE. Evidence synthesis for decision making 3: heterogeneity--subgroups, meta-regression, bias, and biasadjustment. Med Dec Mak. 2013;33(5):618-40.

14. Dias S, Sutton AJ, Ades AE, Welton NJ. Evidence synthesis for decision making 2: a generalized linear modeling framework for pairwise and network metaanalysis of randomized controlled trials. Med Dec Mak. 2013;33(5):607-17.

15. Dias S, Welton NJ, Sutton AJ, Caldwell DM, Lu G, Ades AE. Evidence synthesis for decision making 4: inconsistency in networks of evidence based on randomized controlled trials. Med Dec Mak. 2013;33(5):641-56.

16. Arezzo A, Balague C, Targarona E, Borghi F, Giraudo G, Ghezzo L, Arroyo A Sola-Vera J, De Paolis P, Bossotti M, et al. Colonic stenting as a bridge to surgery versus emergency surgery for malignant colonic obstruction: results of a multicentre randomised controlled trial (ESCO trial). Surg Endosc. 2017; 31(8):3297-305

17. Cheung H, Chung C, Tsang W, Wong J, Yau K, MJAos L. Endolaparoscopic approach vs conventional open surgery in the treatment of obstructing leftsided colon cancer: a randomized controlled trial. Arch Surg. 2009;144(12): 1127-32.

18. Ghazal AH, El-Shazly WG, Bessa SS, El-Riwini MT, Hussein AM. Colonic endolumenal stenting devices and elective surgery versus emergency subtotal/total colectomy in the management of malignant obstructed left colon carcinoma. J Gastrointest Surg. 2013;17(6):1123-9. 
19. Ho KS, Quah HM, Lim JF, Tang CL, Eu KW. Endoscopic stenting and elective surgery versus emergency surgery for left-sided malignant colonic obstruction: a prospective randomized trial. Int J Colorectal Dis. 2012;27(3): 355-62.

20. Pirlet IA, Slim K, Kwiatkowski F, Michot F, Millat BL. Emergency preoperative stenting versus surgery for acute left-sided malignant colonic obstruction: a multicenter randomized controlled trial. Surg Endosc. 2011;25(6):1814-21.

21. Sloothaak DA, van den Berg MW, Dijkgraaf MG, Fockens P, Tanis PJ, van Hooft JE, Bemelman WA, Collaborative Dutch Stent-In study g. Oncological outcome of malignant colonic obstruction in the Dutch Stent-In 2 trial. Br J Surg. 2014;101(13):1751-7.

22. Tung KL, Cheung HY, Ng LW, Chung CC, Li MK. Endo-laparoscopic approach versus conventional open surgery in the treatment of obstructing left-sided colon cancer: long-term follow-up of a randomized trial. Asian J Endosc Surg. 2013;6(2):78-81.

23. van Hooft JE, Bemelman WA, Oldenburg B, Marinelli AW, Holzik MFL, Grubben MJ, Sprangers MA, Dijkgraaf MG, Fockens P. Colonic stenting versus emergency surgery for acute left-sided malignant colonic obstruction: a multicentre randomised trial. Lancet Oncol. 2011:12(4):344-52.

24. Amelung FJ, Draaisma WA, Consten ECJ, Siersema PD, Ter Borg F. Selfexpandable metal stent placement versus emergency resection for malignant proximal colon obstructions. Surg Endosc. 2017;31(11):4532-41.

25. Chen $X Q$, Xue $C R$, Hou $P$, Lin BQ, Zhang JR. Lymphocyte-to-monocyte ratio effectively predicts survival outcome of patients with obstructive colorectal cancer. World J Gastroenterol. 2019;25(33):4970-84.

26. Choi JM, Lee C, Han YM, Lee M, Choi YH, Jang DK, Im JP, Kim SG, Kim JS, Jung HC. Long-term oncologic outcomes of endoscopic stenting as a bridge to surgery for malignant colonic obstruction: comparison with emergency surgery. Surg Endosc. 2014;28(9):2649-55.

27. Consolo P, Giacobbe G, Cintolo M, Tortora A, Fama F, Gioffre Florio M, Pallio S. Colonic acute malignant obstructions: effectiveness of self-expanding metallic stent as bridge to surgery. Turk J Gastroenterol. 2017;28(1):40-5.

28. Dastur JK, Forshaw MJ, Modarai B, Solkar MM, Raymond T, Parker MC. Comparison of short-and long-term outcomes following either insertion of self-expanding metallic stents or emergency surgery in malignant large bowel obstruction. Tech Coloproctol. 2008;12(1):51-5.

29. Erichsen R, Horvath-Puho E, Jacobsen JB, Nilsson T, Baron JA, Sorensen HT. Long-term mortality and recurrence after colorectal cancer surgery with preoperative stenting: a Danish nationwide cohort study. Endoscopy. 2015; 47(6):517-24.

30. Flor-Lorente B, Báguena G, Frasson M, García-Granero A, Cervantes A, Sanchiz V, Peña A, Espí A, Esclapez P, García-Granero E. Self-expanding metallic stent as a bridge to surgery in the treatment of left colon cancer obstruction: cost-benefit analysis and oncologic results. Cirugía Española (English Edition). 2017;95(3):143-51.

31. Gorissen K, Tuynman JB, Fryer E, Wang L, Uberoi R, Jones OM, Cunningham $\mathrm{C}$, Lindsey I. Local recurrence after stenting for obstructing left-sided colonic cancer. Br J Surg. 2013;100(13):1805-9.

32. Guo MG, Feng Y, Zheng Q, Di JZ, Wang Y, Fan YB, Huang XY. Comparison of self-expanding metal stents and urgent surgery for left-sided malignant colonic obstruction in elderly patients. Dig Dis Sci. 2011;56(9):2706-10.

33. Han L, Song X, Yu B, Zhou M, Zhang L, Sun G. Safety evaluation of preoperative stent insertion and clinical analysis on comparison of outcomes between preoperative stent insertion and emergency surgery in the treatment of obstructive left-sided colorectal cancer. Pak J Med Sci. 2020;36(3):376-81.

34. Ho KM, Chan KM, Kwok SY, Lau PY. Colonic self-expanding metal stent (SEMS) as a bridge to surgery in left-sided malignant colonic obstruction: an 8-year review. Surg Endosc. 2017;31(5):2255-62.

35. Kavanagh DO, Nolan B, Judge C, Hyland JM, Mulcahy HE, O'Connell PR, Winter DC, Doherty GA. A comparative study of short- and medium-term outcomes comparing emergent surgery and stenting as a bridge to surgery in patients with acute malignant colonic obstruction. Dis Colon Rectum. 2013;56(4):433-40

36. Kim MK, Kye BH, Lee IK, Oh ST, Ahn CH, Lee YS, Lee SC, Kang WK. Outcome of bridge to surgery stenting for obstructive left colon cancer. ANZ J Surg. 2017;87(12):E245-50.

37. Kim SJ, Kim HW, Park SB, Kang DH, Choi CW, Song BJ, Hong JB, Kim DJ, Park $\mathrm{BS}$, Son GM. Colonic perforation either during or after stent insertion as a bridge to surgery for malignant colorectal obstruction increases the risk of peritoneal seeding. Surg Endosc. 2015;29(12):3499-506.
38. Kwak MS, Kim WS, Lee JM, Yang DH, Yoon YS, Yu CS, Kim JC, Byeon JS. Does stenting as a bridge to surgery in left-sided colorectal cancer obstruction really worsen oncological outcomes? Dis Colon Rectum. 2016; 59(8):725-32.

39. Lee GJ, Kim HJ, Baek JH, Lee WS, Kwon KA. Comparison of short-term outcomes after elective surgery following endoscopic stent insertion and emergency surgery for obstructive colorectal cancer. Int J Surg. 2013;11(6): 442-6.

40. Lim TZ, Chan DKH, Tan KK. Endoscopic stenting does not worsen long term outcomes amongst patients presenting with obstruction from colorectal cancers. Ann Surg Oncol. 2017;24(6):1618-25.

41. Lovero R, Losurdo G, La Fortezza RF, Spirito F, Di Leo A, Andriulli A, Gentile M. Endoscopic stenting for colorectal cancer obstruction as a bridge-tosurgery strategy. Eur J Clin Invest. 2020:e13252.

42. Morita S, Yamamoto K, Ogawa A, Naito A, Mizuno H, Yoshioka S, Matsumura T, Ohta K, Suzuki R, Matsuda C, et al. Benefits of using a self-expandable metallic stent as a bridge to surgery for right- and left-sided obstructive colorectal cancers. Surg Today. 2019;49(1):32-7.

43. Ng KC, Law WL, Lee YM, Choi HK, Seto CL, Ho JW. Self-expanding metallic stent as a bridge to surgery versus emergency resection for obstructing leftsided colorectal cancer: a case-matched study. J Gastrointest Surg. 2006; 10(6):798-803

44. Park J, Lee HJ, Park SJ, Hur H, Min BS, Cheon JH, Kim TI, Kim NK, Kim WH. Longterm outcomes after stenting as a bridge to surgery in patients with obstructing left-sided colorectal cancer. Int J Colorectal Dis. 2018;33(6):799-807.

45. Park SJ, Lee KY, Kwon SH, Lee SH. Stenting as a bridge to surgery for obstructive colon cancer: does it have surgical merit or oncologic demerit? Ann Surg Oncol. 2016;23(3):842-8.

46. Rodrigues-Pinto E, Morais R, Coelho C, Pereira P, Repici A, Macedo G. Bridge-to-surgery versus emergency surgery in the management of leftsided acute malignant colorectal obstruction - efficacy, safety and long-term outcomes. Dig Liver Dis. 2019;51(3):364-72.

47. Sabbagh C, Browet F, Diouf M, Cosse C, Brehant O, Bartoli E, Mauvais F, Chauffert B, Dupas JL, Nguyen-Khac E, et al. Is stenting as "a bridge to surgery" an oncologically safe strategy for the management of acute, leftsided, malignant, colonic obstruction? A comparative study with a propensity score analysis. Ann Surg. 2013;258(1):107-15.

48. van den Berg M, Sloothaak D, Dijkgraaf $M$, van der Zaag E, Bemelman W, Tanis P, Bosker R, Fockens $\mathrm{P}$, ter Borg F, JJTBjos $\vee \mathrm{H}$. Bridge-to-surgery stent placement versus emergency surgery for acute malignant colonic obstruction. 2014;101(7):867-73.

49. Yan FH, Lou Z, Liu XS, Wang Z, Xu XD, Gao YJ, He J, Wang H, Fu CG, Zhang $W$, et al. Long-term oncological outcomes of endoscopic stenting as a bridge to surgery versus emergency surgery for malignant colorectal obstruction: a comparative study. J Laparoendosc Adv Surg Tech A. 2017; 27(6):611-7

50. Yang SY, Park YY, Han YD, Cho MS, Hur H, Min BS, Lee KY, Kim NK. Oncologic outcomes of self-expandable metallic stent as a bridge to surgery and safety and feasibility of minimally invasive surgery for acute malignant colonic obstruction. Ann Surg Oncol. 2019;26(9):2787-96.

51. Amelung FJ, Ter Borg F, Consten EC, Siersema PD, Draaisma WA. Deviating colostomy construction versus stent placement as bridge to surgery for malignant left-sided colonic obstruction. Surg Endosc. 2016;30(12):5345-55.

52. Mege D, Sabbagh C, Manceau G, Bridoux V, Lakkis Z, Momar D, Sielezneff I, Karoui M, Group AFCW. What is the best option between primary diverting stoma or endoscopic stent as a bridge to surgery with a curative intent for obstructed left colon cancer? results from a propensity score analysis of the french surgical association multicenter cohort of 518 patients. Ann Surg Oncol. 2019;26(3):756-64.

53. Veld JV, Amelung FJ, Borstlap WAA, van Halsema EE, Consten ECJ, Siersema PD, ter Borg F, van der Zaag ES, de Wilt JHW, Fockens P, et al. Comparison of decompressing stoma vs stent as a bridge to surgery for left-sided obstructive colon cancer. JAMA Surg. 2020;155:3.

54. Amelung FJ, Consten ECJ, Siersema PD, Tanis PJ. A population-based analysis of three treatment modalities for malignant obstruction of the proximal colon: acute resection versus stent or stoma as a bridge to surgery. Ann Surg Oncol. 2016;23(11):3660-8.

55. Oistamo E, Hjern F, Blomqvist L, Falken Y, Pekkari K, Abraham-Nordling M. Emergency management with resection versus proximal stoma or stent treatment and planned resection in malignant left-sided colon obstruction. World J Surg Oncol. 2016;14(1):232. 
56. Tanis PJ, Paulino Pereira NR, van Hooft JE, Consten EC, Bemelman WA, Dutch Surgical Colorectal A. Resection of obstructive left-sided colon cancer at a national level: a prospective analysis of short-term outcomes in 1,816 patients. Dig Surg. 2015;32(5):317-24.

57. Hosono M, Matsuda T, Yamashita K, Hasegawa H, Yamamoto M, Kanaji S, Oshikiri T, Nakamura T, Sumi Y, Suzuki S, et al. Successful single-stage laparoscopic surgery using a preoperative self-expanding metallic stent in patients with obstructive colorectal cancer. Asian J Endosc Surg. 2019;12(4): 401-7.

58. Kagami S, Funahashi K, Ushigome M, Koike J, Kaneko T, Koda T, Kurihara A, Nagashima Y, Yoshino Y, Goto M, et al. Comparative study between colonic metallic stent and anal tube decompression for Japanese patients with leftsided malignant large bowel obstruction. World J Surg Oncol. 2018;16:1

59. Sato R, Oikawa M, Kakita T, Okada T, Oyama A, Abe T, Yazawa T, Tsuchiya H, Akazawa N, Ohira T, et al. Comparison of the long-term outcomes of the self-expandable metallic stent and transanal decompression tube for obstructive colorectal cancer. Ann Gastroenterol Surg. 2019;3(2):209-16.

60. Yang L, Ma W, Wang M, Zhang R, Bi T, Zhou S. Efficacy of intestinal obstruction stent combined with laparoscopic surgery and neoadjuvant chemotherapy in patients with obstructive colorectal cancer. Oncol Lett. 2019;18(2):1931-7.

61. Kawachi J, Kashiwagi H, Shimoyama R, Isogai N, Fukai R, Miyake K, Egashira $\mathrm{H}$, Sugitani A, Ogino $\mathrm{H}$. Comparison of efficacies of the self-expandable metallic stent versus transanal drainage tube and emergency surgery for malignant left-sided colon obstruction. Asian J Surg. 2018:41(5):498-505.

62. Jiang JK, Lan YT, Lin TC, Chen WS, Yang SH, Wang HS, Chang SC, Lin JK. Primary vs. delayed resection for obstructive left-sided colorectal cancer: impact of surgery on patient outcome. Dis Colon Rectum. 2008;51(3):306-11.

63. van Hooft JE, Veld JV, Arnold D, Beets-Tan RGH, Everett S, Gotz M, van Halsema EE, Hill J, Manes G, Meisner S, et al. Self-expandable metal stents for obstructing colonic and extracolonic cancer: European Society of Gastrointestinal Endoscopy (ESGE) Guideline - Update 2020. Endoscopy. 2020;52(5):389-407.

64. Arezzo A, Passera R, Secco GL, Verra M, Bonino MA, Targarona E, Endoscopy MMJG. Stent as bridge to surgery for left-sided malignant colonic obstruction reduces adverse events and stoma rate compared with emergency surgery: results of a systematic review and meta-analysis of randomized controlled trials. Gastrointestinal Endoscopy. 2017:86(3):416-26.

65. Takashi H, Okabayashi K, Tsuruta M, Hasegawa H, Yahagi M, Surgery KYJWjo. Self-expanding metallic stents versus surgical intervention as palliative therapy for obstructive colorectal cancer: a meta-analysis. World J Surg. 2015:39(8):2037-44.

66. Allievi N, Ceresoli M, Fugazzola P, Montori G, Coccolini F, Oncology ALJljos. Endoscopic stenting as bridge to surgery versus emergency resection for left-sided malignant colorectal obstruction: an updated meta-analysis. Int J Surg Oncol. 2017:2863272.

67. Huang X, LV B, Zhang S, Tract MLJJogsojotSfSotA. Preoperative colonic stents versus emergency surgery for acute left-sided malignant colonic obstruction: a meta-analysis. J Gastroin Surg. 2014;18(3):584-91.

68. Wang X, He J, Chen X, Surgery YQJljo. Stenting as a bridge to resection versus emergency surgery for left-sided colorectal cancer with malignant obstruction: a systematic review and meta-analysis. Int J Surg. 2017:48:64-8.

69. Cennamo V, Luigiano C, Coccolini F, Fabbri C, Bassi M, Giuseppe d C, Ceroni L, Maimone A, Ravelli P, Disease ALJljoc. Meta-analysis of randomized trials comparing endoscopic stenting and surgical decompression for colorectal cancer obstruction. Int J Colorectal Dis. 2013;28(6):855-63.

70. Matsuda A, Miyashita M, Matsumoto S, Matsutani T, Sakurazawa N, Takashi G, Kishi T, Oncology UEJAos. Comparison of long-term outcomes of colonic stent as "bridge to surgery" and emergency surgery for malignant largebowel obstruction: a meta-analysis. Ann Surg Oncol. 2015;22(2):497-504.

71. Foo CC, Poon SHT, Chiu RHY, Lam WY, Cheung LC, Endoscopy LWJS. Is bridge to surgery stenting a safe alternative to emergency surgery in malignant colonic obstruction: a meta-analysis of randomized control trials. Surg Endoscop. 2019;33(1):293-302.

72. Amelung FJ, Burghgraef TA, Tanis PJ, van Jeanin Hooft E, Ter Borg F, Siersema PD, Bemelman WA, Oncology/hematology CEJCri. Critical appraisal of oncological safety of stent as bridge to surgery in left-sided obstructing colon cancer; a systematic review and meta-analysis. Crit Rev Oncol. 2018; 131:66-75.

73. Cao Y, Gu J, Deng S, Li J, Wu K, Disease CKIljoc. Long-term tumour outcomes of self-expanding metal stents as 'bridge to surgery' for the treatment of colorectal cancer with malignant obstruction: a systematic review and meta-analysis. Int J Colorectal Dis. 2019;34(11):1827-38.

74. Zhang Y, Shi J, Shi B, Song CY, Xie WF, Endoscopy CYJS. Self-expanding metallic stent as a bridge to surgery versus emergency surgery for obstructive colorectal cancer: a meta-analysis. Surg Endoscop. 2012;26(1): $110-9$.

75. VJAotRCoSoE T. Emergency management of malignant acute left-sided colonic obstruction. Ann Royal Coll Surg Eng. 2008;90(3):181-6.

76. Matsuda A, Yamada T, Matsumoto S, Sakurazawa N, Kawano Y, Sekiguchi K, Matsutani T, Miyashita M, Today YHJS. Short-term outcomes of a selfexpandable metallic stent as a bridge to surgery vs. a transanal decompression tube for malignant large-bowel obstruction: a meta-analysis. Surg Tod. 2019:49(9):728-37.

77. Li C, Guo S, NJJocg W. Decompression of acute left-sided malignant colorectal obstruction: comparing transanal drainage tube with metallic stent. J Clin Gastroenterol. 2014;48(5):e37-42.

78. Tanaka T, Furukawa A, Murata K, TJDotc S. Rectum: Endoscopic transanal decompression with a drainage tube for acute colonic obstruction: clinical aspects of preoperative treatment. Dis Colon Rectum. 2001;44(3):418-22.

79. Ahn J, Hong S, Chang D, Kim Y, EJWjogo K. Efficacy of uncovered selfexpandable metallic stent for colorectal obstruction by extracolonic malignancy. World J Gastrointes Oncol. 2020;12(9):1005-13.

80. Takeyama H, Kitani K, Wakasa T, Tsujie M, Fujiwara Y, Mizuno S, Yukawa M, Ohta Y, MJDeojotJGES I. Self-expanding metallic stent improves histopathologic edema compared with transanal drainage tube for malignant colorectal obstruction. Digest Endoscop. 2016;28(4):456-64.

\section{Publisher's Note}

Springer Nature remains neutral with regard to jurisdictional claims in published maps and institutional affiliations.

\section{Ready to submit your research? Choose BMC and benefit from:}

- fast, convenient online submission

- thorough peer review by experienced researchers in your field

- rapid publication on acceptance

- support for research data, including large and complex data types

- gold Open Access which fosters wider collaboration and increased citations

- maximum visibility for your research: over $100 \mathrm{M}$ website views per year

At BMC, research is always in progress.

Learn more biomedcentral.com/submissions 